\title{
Regulation Mechanism of HBV cccDNA
}

\author{
Jun Cheng, Min Quan, Min Li, Shun-ai Liu and Qi Wang
}

Covalently closed circular (ccc) DNA of hepatitis B virus (HBV) existed in the nuclei of HBV infected hepatocytes with a half-life time of 14.3 years in a mathematic model. Viral protein feedback regulation in HBV life cycle to maintain vital viral replication is an important mechanism. Interleukin-6, epithelial growth factor, heme oxygenase-1, histones, and hepatocyte nuclear factors are demonstrated as the key regulators for HBV life cycle. $\mathrm{CpG}$ island structure and methylation status are involved in the regulation of HBV DNA replication. Nucleos(t)ide analogues are widely used in the clinical practice for the treatment of chronic hepatitis B patients, although no evidence indicating a direct inhibiton of HBV cccDNA. In the future, along with the study of HBV life cycle, new drugs including RNA interference technique, will pave the way to eliminate the HBV cccDNA from infected hepatocytes resulting final cure of chronic hepatitis B.

Key words: Hepatitis B virus (HBV); Covalently closed circular (ccc) DNA; HBV life cycle; CpG island structure; RNA interference technique

$\mathrm{H}$ epatitis B virus (HBV) contains a small, partially double-stranded, relaxed circular (RC) DNA genome. ${ }^{1}$ RC DNA needs to be converted to covalently closed circular (ccc) DNA, which serves as the template for all viral RNA transcription. ${ }^{2}$ Presently, antiviral drugs against HBV including interferon- $\alpha($ IFN- $\alpha) /$ pegylated IFN (PEG-IFN) and nucleos(t)ide analogues (NUC) are main therapies for chronic hepatitis B (CHB) patients. ${ }^{3}$ However, the cccDNA is still a problem for further study. ${ }^{4}$ Formation and decay of cccDNA in the liver infected by HBV has been investigated for a long time, many of the mechanisms are largely unknown. The study on the cccDNA will pave the way for final resolution of HBV infected patients. ${ }^{5}$

\section{IMPLICATIONS OF HBV CCCDNA IN CLINICAL SAMPLES}

Takkenberg et al found plasma cccDNA levels were higher in $\mathrm{HBeAg}$ positive samples than in $\mathrm{HBeAg}$ negative samples. ${ }^{6}$ Levels of total HBV DNA and HBV genotype did not influence cccDNA detection. ALT levels and hepatic activity index (HAI)-score were not correlated with plasma cccDNA levels. These findings suggest that cccDNA levels in plasma are not the result of increased hepatocyte degeneration, but indicate that other mechanisms might be responsible.

Coffin et al studied the cases with HBV DNA in liver and peripheral blood mononuclear cell (PBMC),

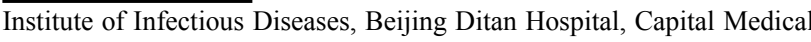
University. No.8 East Jingshun Street, Chaoyang District, Beijing 100015, China

Correspondence: Jun Cheng, E-mail: jun.cheng.ditan@gmail.com and tested for cccDNA. HBV cccDNA was detected in all liver samples. ${ }^{7}$ For HBV replicates in hepatocytes, no doubt cccDNA could be detected in liver tissue or cultured hepatocytes. But it is unclear that cccDNA could be detected in circulation or PBMC, which may serve as a reservoir for the maintenance of infection. Mazet-Wagner et al developed a real-time PCR quantitation of cccDNA in PBMC. ${ }^{8}$ HBV DNA was detected in the serum and PBMC, with less than $1 \%$ in the cccDNA form. Cabrerizo et al also explored the cccDNA levels in PBMC of CHB patients. ${ }^{9} \mathrm{HBV}$ cccDNA was detected in $47 \%$ of the samples. Köck et al examined whether the PBMC can be used to establish an in vitro infection system for $\mathrm{HBV} .^{10}$ Attempts to detect cccDNA after incubation of PBMC with HBV failed. So it could be postulated that all previous observations could be explained by adsorbed virus.

The decline of liver cccDNA is used as a response marker in antiviral therapy. Zhou et al confirmed that $\mathrm{HBe} A g$ production is dependent upon cccDNA in HepAD38 cell cultures and may serve as a cccDNA surrogate in antiviral screening assays. ${ }^{11}$ Undetectable intrahepatic cccDNA level predicts low risk recurrence after orthotopic liver transplantation (OLT). Yasunaka et al showed pre-OLT serum HBV DNA and HBcrAg levels correlated linearly with post-OLT cccDNA levels. High serum HBV DNA and HBcrAg levels at the time of OLT, were associated with high levels of post-OLT cccDNA. ${ }^{12}$ Faria et al detected cccDNA in hepatocellular carcinoma (HCC) more frequently suggest that HBV replication in tumor cells may contribute to HBV recurrence post-OLT. ${ }^{13}$ 
But Hussain et al found that presence of intrahepatic cccDNA is not predictive of HBV recurrence after liver transplantation. ${ }^{14}$ Hosaka et al found HBcrAg is a predictor of the post-treatment recurrence of HCC during antiviral therapy. Serum HBcrAg and intrahepatic cccDNA suppression by NUC may be important to prevent $\mathrm{HCC}$ recurrence. ${ }^{15}$

Wong et al also found the HBcrAg concentration correlated positively with the level of cccDNA. ${ }^{16}$ Chen et al examined the presence of cccDNA in renal tissues from patients with HBV-related glomerulonephritis, and found patients with HBV-related glomerulonephritis were positive for cccDNA. ${ }^{17}$ Ceccarelli et al demonstrated the importance of cccDNA in prediction of HBV reactivation. ${ }^{18}$

\section{VIRAL AND HOST FACTORS REGULATING FORMATION OF HBV CCCDNA}

\section{Viral factors regulating formation of $\mathrm{HBV}$ cccDNA}

The feedback in HBV replication regulation is an important mechanism to maintain viral replication at an optimal level. Gao et al analyzed the viral factors that may be involved in cccDNA formation regulation, using transient and stable DNA transfections of duck hepatitis B virus (DHBV). ${ }^{19}$ Envelope defect leads to increased cccDNA formation in DHBV, which resulted mainly in increased PF-RC, suggesting that the envelope protein(s) may negatively regulate a step in cccDNA formation that precedes deproteination in DHBV. Lentz et al also demonstrated that ablation of expression of the envelope proteins led to an increase in the level of cccDNA. ${ }^{20}$ Subsequent restoration of envelope protein expression led to a decrease in the level of cccDNA, which inversely correlated with the level of the envelope proteins. They found that the expression of $\mathrm{L}$ protein alone or in combination with $\mathrm{M}$ and/or $\mathrm{S}$ proteins led to a decrease in cccDNA levels, indicating that $\mathrm{L}$ contributes to the regulation of cccDNA. Coexpression of $\mathrm{L}$ and $\mathrm{M}$ led to greater regulation than either $\mathrm{L}$ alone or $\mathrm{L}$ and $\mathrm{S}$. Coexpression of all three envelope proteins was also found to limit completion of plus-strand DNA synthesis, and the degree of this effect correlated with the level of the proteins and virion secretion.

$\mathrm{HBV}$ core antigen ( $\mathrm{HBcAg}$ ) is a main component of the cccDNA minichromosome. HBcAg also affects the formation of cccDNA. Guo et al demonstrated that $\mathrm{HBcAg}$ binds to the $\mathrm{CpG}$ islands of cccDNA and promotes an epigenetic permissive state. In the analysis of the impact of HBcAg on cccDNA epigenetic profile in the liver biopsy samples, it is found that $\mathrm{HBcAg}$ binding to cccDNA occurred preferentially at $\mathrm{CpG}$ island 2, an important region for the regulation of HBV transcription. ${ }^{21}$ Furthermore, the relative abundances of $\mathrm{HBcAg}$ binding to $\mathrm{CpG}$ island 2 were positively correlated with the ratios of RC DNA to cccDNA. Interestingly, the relative abundances of $\mathrm{HBcAg}$ binding to $\mathrm{CpG}$ island 2 were associated with the binding of CREB binding protein (CBP) and with hypomethylation in $\mathrm{CpG}$ island 2 of cccDNA minichromosomes. However, relatively higher amounts of $\mathrm{HBcAg}$ binding to $\mathrm{CpG}$ island 2 of cccDNA were accompanied by lower amounts of HDAC1 binding. Multivariate analysis revealed that the abundances of $\mathrm{HBcAg}$ binding to $\mathrm{CpG}$ island 2 of cccDNA and positive $\mathrm{HBeAg}$ were independent factors associated with the replication of HBV. Apparently, $\mathrm{HBcAg}$ is a positive regulator of $\mathrm{HBV}$ transcription and replication, maintaining the permissive epigenetic state in the critical region of the cccDNA minichromosomes.

Chou et al used a modified 1.3-fold HBV genome to examine the transcriptional activity of cccDNA and the effect of the HBxAg protein on transcriptional regulation. ${ }^{22}$ After harvesting total RNA from transfected cells or stable lines, they specifically identified and monitored the transcripts from cccDNA. In this approach, it was found that the transcriptional activity of cccDNA was significantly regulated by the $\mathrm{HBxAg}$ protein. Lucifora et al also observed that cells inoculated with $\mathrm{HBxAg}$-deficient $\mathrm{HBV}$ particles $[\mathrm{HBV}(\mathrm{x}-)]$ did not lead to productive HBV infection contrary to cells inoculated with wild type HBV particles $[\mathrm{HBV}(\mathrm{wt})] .^{23}$ Although equal amounts of nuclear cccDNA demonstrated comparable uptake and nuclear import, active transcription was only observed from $\mathrm{HBV}(\mathrm{wt})$ genomes. Trans-complementation of HBxAg was able to rescue transcription from the HBV (X-) genome and led to antigen and virion secretion, even weeks after infection. Constant expression of HBxAg was necessary to maintain HBV antigen expression and replication. HBxAg is not packaged into virions during assembly but is expressed after infection within the new host cell to allow epigenetic control of HBV transcription from cccDNA. The results demonstrate that $\mathrm{HBxAg}$ is required to initiate and maintain HBV replication and highlight $\mathrm{HBxAg}$ as the key regulator during the natural infection process.

\section{Host factors regulating formation of $\mathrm{HBV}$ cccDNA Interleukin-6}

Interleukin-6 (IL-6) is a pleiotropic cytokine with pivotal functions in the regulation of the biological responses of several target cells including hepatocytes. The level of serum IL- 6 has been reported to be elevated in patients with $\mathrm{CHB}$, liver cirrhosis and HCC and represents the best marker of HBV-related clinical progression as compared with several other cytokines. 
Kuo et al found that IL-6 was able to effectively suppress HBV replication and prevent the accumulation of cccDNA in a human hepatoma cell line. Suppression of HBV replication by IL-6 requires concurrently a moderate reduction of viral transcripts/core proteins and a marked decrease in viral genome-containing nucleocapsids. Studies on the stability of existing viral capsids suggest that the IL- 6 effect on the reduction of genome-containing nucleocapsids is mediated through the prevention of the formation of genome-containing nucleocapsids, which is similar to the effect of IFNs. However, IFN- $\alpha / \beta$ and IFN- $\gamma$ did not participate in the IL-6-induced suppression of HBV replication. ${ }^{24}$

\section{Epithelial growth factor}

Schorr et al found that epithelial growth factor (EGF) induced cell proliferation is associated with a slight increase in cccDNA synthesis and a decrease in viral transcription. ${ }^{25}$ Conversely, transforming growth factor (TGF) $\beta$ blocked cell cycle progression, diminished cccDNA synthesis but increased viral transcription.

\section{Heme oxygenase-1}

Induction of heme oxygenase-1 (HO-1) has been shown to be beneficial in immune-mediated liver damage. Protzer et al investigated the effects of HO-1 induction in models of HBV infection. ${ }^{26}$ In an acute hepatitis B model, liver injury was reduced significantly after HO-1 induction. In addition, HO-1 showed a pronounced antiviral effect, which was confirmed in stably HBVtransfected hepatoma cells and in persistently HBV replicating transgenic mice. It has been showed that HO-1 induction repressed HBV replication directly in hepatocytes at a posttranscriptional step by reducing stability of $\mathrm{HBcAg}$ and thus blocking refill of nuclear cccDNA. Small interfering RNA directed against HO-1 proved that this effect depended on the expression level of HO-1. Besides its hepatoprotective effect, HO-1 showed a pronounced antiviral activity in HBV infection. Therefore, induction of HO-1 might be a novel therapeutic option for inflammatory flares of hepatitis B.

Lucifora et al showed that cccDNA resulted from the recycling of newly synthesized nucleocapsids and was bound to acetylated histones in a chromatin-like structure. HBV particles released into the supernatant of transduced HepG2 cells were infectious in differentiated HepaRG cells. ${ }^{23}$ Several Bac-HBV-1.1 baculoviruses containing HBV strains carrying mutations conferring resistance to lamivudine (LAM) and/or adefovir dipivoxil (ADV) were constructed. Phenotypic analysis of these mutants confirmed the results obtained with the transfection procedures. In conclusion, an improved cell-culture system was established for the transduction of replicationcompetent HBV genomes. This will be useful for future studies of the fitness of HBV mutants.

\section{Histones}

Nuclear cccDNA accumulates in hepatocyte nuclei as a stable minichromosome organized by histone and non-histone viral and cellular proteins. Levrero et al explained the molecular mechanisms regulating cccDNA stability and its transcriptional activity at the RNA, DNA and epigenetic levels may reveal new potential therapeutic targets depleting the cccDNA reservoir. $^{27}$

Belloni et al showed that the cellular histone acetyltransferases CBP, p300, and PCAF/GCN5, and the histone deacetylases HDAC1 and hSirt1 are all recruited in vivo onto the cccDNA. ${ }^{28} \mathrm{p} 300$ recruitment is severely impaired, and cccDNA-bound histones are rapidly hypoacetylated in cells replicating the HBxAg mutant, whereas the recruitment of the histone deacetylases hSirt 1 and HDAC1 is increased and occurs at earlier times. The results further support the existence of a complex network of epigenetic events that influence cccDNA function and HBV replication and identify an epigenetic mechanism (i.e., to prevent cccDNA deacetylation) by which HBxAg controls HBV replication.

The remodeling of HBV minichromosomes such as post-translational modifications of histone proteins plays an important role in regulating HBV replication. Gong et al determined whether other remodeling occurs in addition to acetylation of cccDNA-bound $\mathrm{H} 3$ histones in the presence of HBV replication, a cell culture replication model of HBV was used to assess the dynamic status of acetylation, phosphorylation, and methylation of cccDNA-bound $\mathrm{H} 3$ histones at various times after transient transfection of linear HBV DNA into human hepatoma, HepG2 cells. ${ }^{29} \mathrm{H} 3$ histones bound to cccDNA were found to be phosphorylated, mono-methylated, and acetylated in HepG2 cells containing replicating HBV. The acetylation and methylation status of $\mathrm{H} 3$ histones bound to cccDNA paralleled HBV replication. The results demonstrate that phosphorylation and methylation occur in the remodeling of HBV minichromosomes during HBV replication. The modifications of cccDNA-bound H3 histones were associated with the level of HBV replication. These findings suggest that alterations in the extent of minichromosome remodeling might be a potential target to inhibit HBV replication in the development of effective novel antiviral agents.

Belloni et al showed that IFN- $\alpha$ inhibits HBV replication by decreasing the transcription of pregenomic RNA (pgRNA) and subgenomic RNA from the cccDNA minichromosome, both in cultured cells in which HBV is replicating and in mice whose livers have been repopulated with human hepatocytes and infected with $\mathrm{HBV}^{30}$ Administration of IFN- $\alpha$ resulted in cccDNA-bound histone hypoacetylation as well as 
active recruitment to the cccDNA of transcriptional corepressors. IFN- $\alpha$ treatment also reduced binding of the STAT1 and STAT2 transcription factors to active cccDNA. The inhibitory activity of IFN- $\alpha$ was linked to the IRSE, as IRSE-mutant HBV transcribed less pgRNA and could not be repressed by IFN- $\alpha$ treatment. The results identify a molecular mechanism whereby IFN- $\alpha$ mediates epigenetic repression of cccDNA transcriptional activity, which may assist in the development of novel effective therapeutics.

Pollicino et al used anti-acetyl-H4/-H3 specific antibodies to immunoprecipitate transcriptionally active chromatin revealed that HBV replication is regulated by the acetylation status of the cccDNAbound $\mathrm{H} 3 / \mathrm{H} 4$ histones. ${ }^{31}$ Class I histone deacetylases inhibitors induced an evident increase of both cccDNAbound acetylated H4 and HBV replication. Finally, histones hypoacetylation and histone deacetylase 1 recruitment onto the cccDNA in liver tissue correlated with low HBV viremia in hepatitis B patients. A ChIPbased assay has been developed to analyze, in vitro and ex vivo, the transcriptional regulation of cccDNA minichromosome. The results provide new insights on the regulation of $\mathrm{HBV}$ replication and identify the enzymatic activities that modulate the acetylation of cccDNA-bound histones as new therapeutic targets for anti-HBV drugs.

\section{Hepatocyte nuclear factor 1}

The role of hepatocyte nuclear factor $1 \alpha$ (HNF1 $\alpha)$ in the regulation of $\mathrm{HBV}$ transcription and replication in vivo was investigated using an HNF1 $\alpha$-null HBV transgenic mouse model. HBV transcription was not measurably affected by the absence of the HNF $1 \alpha$ transcription factor. However, intracellular viral replication intermediates were increased in mice lacking functional HNF $1 \alpha$ protein. The increase in encapsidated cytoplasmic replication intermediates in HNF1 $\alpha$-null HBV transgenic mice was associated with the appearance of nonencapsidated nuclear cccDNA. Viral cccDNA was not readily detected in HNF1 $\alpha$ expressing HBV transgenic mice. Raney et al indicated the synthesis of nuclear cccDNA, the proposed viral transcriptional template found in natural infection, is regulated either by subtle alterations in the levels of viral transcripts or by changes in the physiological state of the hepatocyte in this in vivo model of HBV replication. ${ }^{32}$

\section{METHYLATION AND REGULATION OF HBV CCCDNA}

HBV DNA has been shown to contain $\mathrm{CpG}$ islands that are methylated in human tissue, which suggests a role for methylation in regulating viral protein production. It is found that transfection of methylated HBV DNA led to reduced HBV mRNA levels in HepG2 cells, decreased surface and core protein expression in these cells, and decreased secretion of HBV viral proteins into the cell supernatant. ${ }^{33}$ These data provide direct evidence that $\mathrm{CpG}$ islands regulate gene transcription of HBV. Furthermore, methylated cccDNA was found in tumor and nonneoplastic human liver tissues. Finally, an in vitro equivalent of cccDNA showed decreased viral protein production in HepG2 cells after DNA methylation.

Guo et al compared the methylation status of the intrahepatic cccDNA CpG island 2 and HBV replication capability. ${ }^{34} \mathrm{HBV}$ cccDNA was extracted from liver biopsies of $55 \mathrm{HBsAg}$-positive patients with $\mathrm{CHB}$, and was analyzed for methylation status and quantity. The two Hpa II recognition sequences CCpGG in the $\mathrm{CpG}$ island 2 were methylated in infected liver tissues. Positive ratios of cccDNA methylation were significantly higher in $\mathrm{HBeAg}$ negative patients than $\mathrm{HBeAg}$-positive patients. The percentage of methylated-cccDNA/total-cccDNA of $\mathrm{HBeAg-negative} \mathrm{samples} \mathrm{was} \mathrm{significantly} \mathrm{higher}$ than $\mathrm{HBeAg}$-positive samples. Ratios of rcDNA to cccDNA molecules revealed that cccDNA methylation correlated with impaired virion productivity in $\mathrm{HBeAg}$ positive individuals. The bisulfite DNA sequencing showed that methylation density was significantly higher in $\mathrm{HBeAg}$-negative than in $\mathrm{HBeAg}$-positive patients. The methylation level of the $\mathrm{CpG}$ island 2 of the cccDNA in HBeAg-negative patients was higher than that in $\mathrm{HBeAg}$-positive patients, suggesting that cccDNA methylation may be relevant to replication capability of HBV. Kim et al found that variable degrees of $\mathrm{CpG}$ methylation were present in the cccDNA from patients with HBV-LC. ${ }^{35}$ Old age, low serum HBV DNA levels and low virion productivity were significantly associated with elevated cccDNA methylation. Virion productivity of cccDNA was also lower in HepAD38 cells with a higher degree of cccDNA methylation. In vitro transcription assays showed that the transcriptional activity of cccDNA was suppressed by increased methylation of cccDNA.

Guo et al analyzed the binding of $\mathrm{HBcAg}$ to cccDNA and the impact of HBcAg on cccDNA epigenetic profile in the liver biopsy samples of patients with $\mathrm{CHB} .{ }^{36} \mathrm{HBcAg}$ binding to cccDNA occurred preferentially at $\mathrm{CpG}$ island 2, an important region for the regulation of HBV transcription. Furthermore, the relative abundances of $\mathrm{HBcAg}$ binding to $\mathrm{CpG}$ island 2 were positively correlated with the ratios of relaxed circular DNA to cccDNA and the levels of serum HBV DNA in those patients. Interestingly, the relative abundances of $\mathrm{HBcAg}$ binding to $\mathrm{CpG}$ island 2 were associated with the binding of CREB binding protein (CBP) and with hypomethylation in $\mathrm{CpG}$ island 
2 of cccDNA minichromosomes. However, relatively higher amounts of $\mathrm{HBcAg}$ binding to $\mathrm{CpG}$ island 2 of cccDNA were accompanied by lower amounts of HDAC1 binding. Multivariate analysis revealed that the abundances of $\mathrm{HBcAg}$ binding to $\mathrm{CpG}$ island 2 of cccDNA and positive $\mathrm{HBeAg}$ were independent factors associated with the replication of HBV. Apparently, $\mathrm{HBcAg}$ is a positive regulator of $\mathrm{HBV}$ transcription and replication, maintaining the permissive epigenetic state in the critical region of the cccDNA minichromosomes.

\section{RNA INTERFERENCE AND REGULATION OF HBV CCCDNA}

HBV replicates via RNA intermediates, which could serve as targets for RNA interference (RNAi). Progress in RNAi has shed slight on developing a new antiHBV strategy. Li et al showed that siRNA1 markedly inhibited cccDNA replication by targeting nuclear localization signal (NLS) ${ }^{37}$ HBV NLS may serve as a novel RNAi target to combat HBV infection, which can enhance anti-HBV efficacy and overcome the drawbacks of current therapies.

Kim et al used lentiviral vector to express two shRNA sequences against the hepatitis B viral protein $\mathrm{HBxAg}$ (sh1580 and sh1685). ${ }^{35}$ Lentiviral vectors encoding the shRNA against HBV transduced HepAD38 cells with high efficacy. The total intracellular HBV DNA content was significantly reduced by both sh1580 and sh1685. HBV cccDNA was also suppressed significantly. Lentivirusmediated delivery of shRNA against HBxAg can effectively suppress the replication of HBV and reduce cccDNA in cell culture systems.

Panjaworayan et al conducted computational analysis of the PRE sequence revealing several conserved regulatory elements that are predicted to form local secondary structures some of these within known regulatory regions. ${ }^{38}$ Deletion analysis showed that sub-elements of the PRE have different effects on the reporter activity suggesting that the PRE contains multiple regulatory elements. Conserved siRNA targets at nucleotide position nt 1317-1337 and nt 1329-1349 were predicted. Although the siRNA at the position nt 1329-1349 had no effect on the expression of reporter gene, the siRNA target site at the position nt 1317-1337 was observed to significantly decrease expression of the reporter protein. This siRNA also specifically reduced the level of cccDNA in transiently HBV infected cells. The HBV PRE is likely to contain multiple regulatory elements. A conserved target within this region at $\mathrm{nt} 1317-1337$ is an effective siRNA target.

HBV replication was initiated in HepG2 cells by transduction with HBV baculovirus. Subculture of HBV- expressing HepG2 cells post-transduction generates a system in which HBV replication is ongoing and HBV is expressed largely from cccDNA, thus simulating chronic HBV infection. ${ }^{39}$ HepG2 cells were transduced with short hairpin RNA (shRNA)-expressing baculovirus prior to initiation of HBV replication or during chronic HBV replication, and the levels of HBV RNA, HBsAg and replicative intermediates (RI), extracellular (EC) and cccDNA species were measured. HBsAg, HBV RNA and DNA levels were markedly reduced whether cells were transduced with shRNA prior to or during a chronic infection; however, the cccDNA species were only affected when shRNA was administered prior to initiation of infection. It is concluded that RNAi may have a therapeutic value for controlling HBV replication at the level of RI and EC DNA and for reducing establishment of cccDNA during HBV infection. These data support previous findings demonstrating the stability of cccDNA following antiviral therapy. This study also reports the development of a novel HBV baculovirus subculture system that can be used to evaluate antiviral effects on chronic HBV replication.

\section{ANTIVIRALS AND INHIBITION OF HBV CCCDNA}

\section{Interferon $\alpha$ and pegylated interferon inhibit formation of HBV cccDNA}

Both conventional IFN- $\alpha$ and PEG-IFN are playing important part in the treatment of CHB. Tangkijvanich et al evaluated virological response to PEG-IFN therapy. ${ }^{40}$ Responders had significantly lower baseline HBsAg, HBeAg, cccDNA and intrahepatic HBV DNA levels than non-responders. Baseline and reduced levels of $\mathrm{HBsAg}$ and $\mathrm{HBeAg}$ correlated well with cccDNA. Sung et al also found cccDNA is a good predictor of virological response to PEG-IFN. ${ }^{41}$ At the end of treatment, HBV DNA levels correlated well with intrahepatic cccDNA and intrahepatic total HBV DNA levels. Intrahepatic cccDNA and intrahepatic total DNA levels were significantly lower among patients with sustained virologic response. Intrahepatic cccDNA and intrahepatic total HBV DNA levels at the end of therapy are superior to serum HBV DNA as surrogates of sustained virologic response. Takkenberg et al also demonstrated that intrahepatic cccDNA and total intrahepatic HBV DNA were predictive for SVR, at end of treatment in $\mathrm{HBeAg}$ positive patients. ${ }^{42}$ Wursthorn et al used PEG-IFN and ADV to treat HBsAg-positive CHB patients. ${ }^{43}$ Combination therapy led to marked decreases in serum HBV DNA and intrahepatic cccDNA, which was significantly correlated with 
reduced HBsAg.

\section{Nucleos(t)ide analogues inhibit formation of HBV cccDNA}

Nucleos(t)ide analogues (NUC) are playing important part in treatment of CHB. HBV DNA, HBeAg seroconversion, even HBsAg loss are often been taken as surrogate to evaluate antiviral efficacy. But the results regarding the cccDNA levels are controversial. In the future, drug development should be focused on eradication of cccDNA from liver tissue.

\section{Lamivudine}

Chong et al used a stably HBV-producing cell line, 1.3ES2, and examine the dynamic changes of cccDNA in different cellular growth stages. ${ }^{44}$ It is showed that cccDNA increased suddenly in the initial proliferation phase of cell growth, probably attributable to its nuclear replenishment by intracellular nucleocapsids. The amount of cccDNA then decreased dramatically in the cells during their exponential proliferation similar to the loss of extrachromosomal plasmid DNA during cell division, after which it accumulated gradually while the host cells grew to confluency. It is found that cccDNA was reduced in dividing cells and could be removed when proliferating cells were subjected to long term of LAM treatment. Yuen et al test the effect of LAM therapy on the serum cccDNA of CHB patients. There was a significant reduction in the cccDNA levels from baseline to week 24 and week 52. Compared to patients without YMDD mutations, patients with YMDD mutations had significantly less median reduction of cccDNA level. ${ }^{45}$ One-year LAM treatment decreased serum cccDNA level. But Soemohardjo et al insisted on that LAM does not affect the cccDNA of infected hepatocytes; it only inhibits the formation of new viruses. $^{46}$

\section{Adefovir dipivoxil}

Delmas et al determined whether treatment with adefovir dipivoxil (ADV) is able to suppress viral cccDNA both in vitro and in vivo using the DHBV models. ${ }^{47}$ Dose-dependent inhibition of both virion release in culture supernatants and synthesis of intracellular viral DNA was observed. Although cccDNA amplification was inhibited by ADV, cccDNA was not eliminated by antiviral treatment and the de novo formation of cccDNA was not prevented by pretreatment of the cells. The results demonstrate that ADV is a potent inhibitor of DHBV replication that inhibits cccDNA amplification but does not effectively prevent the formation of cccDNA from incoming viral genomes. Werle-Lapostolle et al demonstrated that forty-eight weeks of ADV therapy resulted in a significant decrease in cccDNA. ${ }^{48}$ Changes in cccDNA were correlated with a similar reduction in serum HBsAg titer but not with a decrease in the number of
HBV antigen-positive cells during ADV treatment.

Cheng et al compared cccDNA reduction with relation to liver histology in NUC-naïve chronic hepatitis $\mathrm{B}$ patients receiving oral $\mathrm{ADV}$ antiviral monotherapy. ${ }^{49}$ Intrahepatic cccDNA levels are reduced slightly, and do not differ statistically from the placebo group. Level of intrahepatic cccDNA correlated with Knodell necroinflammation activity and Ishak fibrosis severity before treatment. Multivariate logistic regression analysis indicates that treatment-induced cccDNA reduction is associated with improved necroinflammation and fibrosis. One-year ADV treatment is insufficient for cccDNA eradication, ADV therapy may improve liver histology, probably by suppressing intrahepatic cccDNA. Entecavir

Nucleoside analogues inhibit HBV replication. Entecavir (ETV) has also been shown to reduce cccDNA to undetectable levels in woodchucks chronically infected with hepatitis virus. Wong et al assessed the effect of ETV therapy on intrahepatic total HBV DNA and cccDNA levels. ${ }^{50}$ Entecavir reduced serum viral load, intrahepatic total HBV DNA, and cccDNA. Residual HBV DNA can be detected following the resolution of acute HBV infection. The study on DHBV infected ducks indicated that $\sim 80 \%$ of residual DHBV DNA in the liver is in cccDNA form, suggesting that viral DNA synthesis is suppressed. Reaiche et al checked more directly if maintenance of residual DHBV cccDNA is dependent upon ongoing viral DNA synthesis. ${ }^{51}$ Ducks that recovered from acute DHBV infection were divided into 2 groups and treated with the antiviral drug ETV or placebo. No major differences in the stability of cccDNA or levels of residual cccDNA were observed in liver biopsy tissues taken 95 days apart from ETV treated and placebo control ducks. The data suggest that residual DHBV cccDNA is highly stable and present in a cell population with a rate of turnover similar to normal, uninfected hepatocytes.

\section{Clevudine}

Anderson et al demonstrated that clevudine (CLV) is distinguished from other oral agents by its sustained suppression of HBV DNA for several months after cessation of therapy. ${ }^{52} \mathrm{CLV}$ is differentiated by significant reduction of cccDNA in animal models. In treatment-naïve patients, $59 \%$ of $\mathrm{HBeAg}$-positive and $75 \%$ of $\mathrm{HBeAg}$-negative patients had undetectable HBV DNA after 24 weeks of treatment. On the contrary, Seignères et al have evaluated the antiviral activity of CLV in the DHBV model, and failed to demonstrate the reduction of cccDNA.$^{53}$ Administration of CLV for 4 weeks efficiently suppressed viremia and viral replication. However, no viral clearance from the liver was observed, suggesting that the antiviral effect of CLV was not sufficient for cccDNA suppression and HBV eradication from infected cells. 


\section{NEW AGENTS INHIBITING FORMATION OF HBV CCCDNA}

Quintero et al conducted a search for natural products capable of inhibiting HBV replication. The hydroalcoholic extracts of 31 species from the Venezuelan Amazonian rain forest on the cell line HepG2 2.2.15, which constitutively produces HBV. ${ }^{54}$ The species Euterpe precatoria, Jacaranda copaia, Jacaranda obtusifolia, Senna silvestris, Warscewiczia coccinea and Vochysia glaberrima exerted some degree of inhibition on HBV replication. The leaves of $W$. coccinea showed a significant antiviral activity: $80 \%$ inhibition with 100 $\mu \mathrm{g} / \mathrm{ml}$ of extract. This extract also exerted inhibition on cccDNA production. Initial fractionation using organic solvents of increasing polarity and water showed that the ethanol fraction was responsible for most of the antiviral inhibitory activities. It was concluded that Warscewiczia coccinea extract showed inhibition of HBV replication. Bioassay-guided purification of this fraction may allow the isolation of an antiviral compound with inhibitory activity.

Mycophenolate mofetil (MMF), the morpholinoethyl ester of mycophenolic acid (MPA), is currently used as an immunosuppressive agent in kidney transplant recipients. After oral administration, MMF is hydrolysed to MPA, the active compound, which is a potent inhibitor of inosine monophosphate dehydrogenase (IMP-DH). Inhibition of this enzyme results in a depletion of the intracellular GTP and dGTP pools. MPA has been shown to inhibit the replication of a number of viruses. To examine whether MPA also has an inhibitory effect on HBV replication, Gong et al used cultures of primary human hepatocytes and HBV-transfected, HepG2 2.2.15 cells for antiviral effects of MPA. ${ }^{55}$ After in vitro infection with $\mathrm{HBV}$ in human hepatocytes, cccDNA and HBV mRNAs were detectable in the cells during the 10 days following infection. HBV DNA and HBsAg were also secreted into the culture medium. In the presence of 10 $\mu \mathrm{g} / \mathrm{ml}$ MPA (the therapeutic serum level of MPA as an immunosuppressive agent) in culture medium, cccDNA and HBV mRNAs became undetectable 5 days after treatment was started. The secretion of HBV DNA and HBsAg into the medium was also markedly reduced. No cytotoxic effect of the drug was noted during the experiments. The effect of MPA on HBV replication was abolished by the presence of guanosine $(50 \mu \mathrm{g} / \mathrm{ml})$. In HepG2 2.2.15 cells (which contain an integrated tandem dimer of the HBV genome), MPA treatment had no significant inhibitory effect on the secretion of HBV DNA and HBsAg into the culture medium. HBV cccDNA and HBV mRNAs in HepG2 2.2.15 cells were also not affected. The observed effect of MPA on HBV replication in primary human hepatocyte cultures may involve only episomal replication and may have clinical implications, especially before integration of HBV DNA into the host genome.

Nucleoside analogs can decrease virus production by inhibiting the viral polymerase; however, complete clearance by these drugs is not common because of the persistence of the HBV episome. HBV DNA is present in the nucleus as cccDNA form, where it drives viral transcription and progeny virus production. HBV cccDNA is not the direct target of antiviral nucleoside analogs and is the source of HBV reemergence when antiviral therapy is stopped. To target cccDNA, six different zinc finger proteins (ZFP) were designed to bind DNA sequences in the DHBV enhancer region. ${ }^{56}$ After the binding kinetics were assessed by using electrophoretic mobility shift assays and surface plasmon resonance, two candidates were focused on for further study. The ZFPs were cloned into a eukaryotic expression vector and cotransfected into longhorn male hepatoma cells with the plasmid pDHBV1.3, which replicates the DHBV life cycle. In the presence of each ZFP, viral RNA was significantly reduced, and protein levels were dramatically decreased. As a result, intracellular viral particle production was also significantly decreased. In summary, designed ZFPs are able to bind to the DHBV enhancer and interfere with viral transcription, resulting in decreased production of viral products and progeny virus genomes.

\section{REFERENCES}

1. Spangenberg HC, Thimme R, Blum HE. Tracking cccDNA in chronic HBV infection. Hepatology 2004;39:1736-1738.

2. Lucifora J, Arzberger S, Durantel D, Belloni L, Strubin M, Levrero M, et al. Hepatitis B virus X protein is essential to initiate and maintain virus replication after infection. J Hepatol 2011;55:996-1003.

3. Chan HL, Thompson A, Martinot-Peignoux M, Piratvisuth T, Cornberg M, Brunetto MR, et al. Hepatitis B surface antigen quantification: why and how to use it in 2011-a core group report. $\mathrm{J}$ Hepatol 2011;55:1121-1131.

4. Locarnini S, Zoulim F. Molecular genetics of HBV infection. Antivir Ther 2010;15 (Suppl 3):s3-s14.

5. Lewin S, Walters T, Locarnini S. Hepatitis B treatment: rational combination chemotherapy based on viral kinetic and animal model studies. Antiviral Res 2002;55:381-396.

6. Takkenberg RB, Zaaijer HL, Menting S, Weegink CJ, Terpstra $\mathrm{V}$, Cornelissen M, et al. Detection of hepatitis B virus covalently closed circular DNA in paraffin-embedded and cryo-preserved liver biopsies of chronic hepatitis B patients. Eur J Gastroenterol Hepatol 2010;22:952-960

7. Coffin CS, Mulrooney-Cousins PM, van Marle G, Roberts JP, Michalak TI, Terrault NA. Hepatitis B virus quasispecies in hepatic and extrahepatic viral reservoirs in liver transplant recipients on prophylactic therapy. Liver Transpl 2011;17:955-962.

8. Mazet-Wagner AA, Baclet MC, Loustaud-Ratti V, Denis F, Alain S. Real-time PCR quantitation of hepatitis B virus total DNA and covalently closed circular DNA in peripheral blood mononuclear cells from hepatitis B virus-infected patients. J Virol Methods 2006;138:70-79.

9. Cabrerizo M, Bartolomé J, Caramelo C, Barril G, Carreno V. Molecular analysis of hepatitis B virus DNA in serum and peripheral blood mononuclear cells from hepatitis B surface antigen-negative cases. Hepatology 2000;32:116-123. 
10. Köck J, Rösler C, Zhang JJ, Blum HE, Nassal M, Thoma C. Generation of covalently closed circular DNA of hepatitis B viruses via intracellular recycling is regulated in a virus specific manner. PLoS Pathog 2010;6:e1001082.

11. Zhou T, Guo H, Guo JT, Cuconati A, Mehta A, Block TM. Hepatitis B virus e antigen production is dependent upon covalently closed circular (ccc) DNA in HepAD38 cell cultures and may serve as a cccDNA surrogate in antiviral screening assays. Antiviral Res 2006;72:116-124.

12. Yasunaka T, Takaki A, Yagi T, Iwasaki Y, Sadamori H, Koike K, et al. Serum hepatitis B virus DNA before liver transplantation correlates with $\mathrm{HBV}$ reinfection rate even under successful low-dose hepatitis B immunoglobulin prophylaxis. Hepatol Int 2011. [Epub ahead of print] PMID:21484119 [PubMed - as supplied by publisher] doi: 10.1002/ 1t.22312.

13. Faria LC, Gigou M, Roque-Afonso AM, Sebagh M, Roche B, Fallot $\mathrm{G}$, et al. Hepatocellular carcinoma is associated with an increased risk of hepatitis B virus recurrence after liver transplantation. Gastroenterology 2008;134:1890-1899.

14. Hussain M, Soldevila-Pico C, Emre S, Luketic V, Lok AS; NIH HBVOLT Study Group. Presence of intrahepatic (total and ccc) HBV DNA is not predictive of $\mathrm{HBV}$ recurrence after liver transplantation. Liver Transpl 2007;13:1137-1144.

15. Hosaka T, Suzuki F, Kobayashi M, Hirakawa M, Kawamura Y, Yatsuji $\mathrm{H}$, et al. HBcrAg is a predictor of post-treatment recurrence of hepatocellular carcinoma during antiviral therapy. Liver Int 2010;30:1461-1470.

16. Wong DK, Tanaka Y, Lai CL, Mizokami M, Fung J, Yuen MF. Hepatitis B virus core-related antigens as markers for monitoring chronic hepatitis B infection. J Clin Microbiol 2007;45:3942-3947.

17. Chen L, Wu C, Fan X, Gao J, Yin H, Wang T, et al. Replication and infectivity of hepatitis B virus in HBV-related glomerulonephritis. Int J Infect Dis 2009;13:394-398.

18. Ceccarelli L, Salpini R, Sarmati L, Svicher V, Bertoli A, Sordillo P, et al. Late hepatitis B virus reactivation after lamivudine prophylaxis interruption in an anti-HBs-positive and anti-HBc-negative patient treated with rituximab-containing therapy. J Infect 2012;65:180-183.

19. Gao W, Hu J. Formation of hepatitis B virus covalently closed circular DNA: removal of genome-linked protein. J Virol 2007;81:6164-6174.

20. Lentz TB, Loeb DD. Roles of the envelope proteins in the amplification of covalently closed circular DNA and completion of synthesis of the plus-strand DNA in hepatitis B virus. J Virol 2011;85:11916-11927.

21. Guo YH, Li YN, Zhao JR, Zhang J, Yan Z. HBc binds to the CpG islands of HBV cccDNA and promotes an epigenetic permissive state. Epigenetics 2011;6:720-726.

22. Chou YC, Jeng KS, Chen ML, Liu HH, Liu TL, Chen YL, et al. Evaluation of transcriptional efficiency of hepatitis B virus covalently closed circular DNA by reverse transcription-PCR combined with the restriction enzyme digestion method. J Virol 2005;79:1813-1823.

23. Lucifora J, Durantel D, Belloni L, Barraud L, Villet S, Vincent IE, et al. Initiation of hepatitis B virus genome replication and production of infectious virus following delivery in HepG2 cells by novel recombinant baculovirus vector. J Gen Virol 2008;89:1819-1828.

24. Kuo TM, Hu CP, Chen YL, Hong MH, Jeng KS, Liang CC, et al. HBV replication is significantly reduced by IL-6. J Biomed Sci 2009; $16: 41$.

25. Schorr O, Borel C, Trepo C, Zoulim F, Hantz O. Effects of liver growth factors on hepadnavirus replication in chronically infected duck hepatocytes. J Hepatol 2006;44:842-847.

26. Protzer U, Seyfried S, Quasdorff M, Sass G, Svorcova M, Webb D, et al. Antiviral activity and hepatoprotection by heme oxygenase-1 in hepatitis B virus infection. Gastroenterology 2007;133:1156-1165.

27. Levrero M, Pollicino T, Petersen J, Belloni L, Raimondo G, Dandri M. Control of cccDNA function in hepatitis B virus infection. J Hepatol 2009;51:581-592.

28. Belloni L, Pollicino T, De Nicola F, Guerrieri F, Raffa G, Fanciulli M, et al. Nuclear HBx binds the HBV minichromosome and modifies the epigenetic regulation of cccDNA function. Proc Natl Acad Sci USA 2009;106:19975-19979.

29. Gong Q, Chen S, Guo J, Sun H, Zheng G, Liu Q, et al. Chromosome remodeling related to hepatitis B virus replication in HepG2 cells. DNA Cell Biol 2011;30:347-354.
30. Belloni L, Allweiss L, Guerrieri F, Pediconi N, Volz T, Pollicino T, et al. IFN- $\alpha$ inhibits HBV transcription and replication in cell culture and in humanized mice by targeting the epigenetic regulation of the nuclear cccDNA minichromosome. J Clin Invest 2012;122:529-537.

31. Pollicino T, Raffa G, Santantonio T, Gaeta GB, Iannello G, Alibrandi $\mathrm{A}$, et al. Replicative and transcriptional activities of hepatitis B virus in patients coinfected with hepatitis B and hepatitis delta viruses. J Virol 2011;85:432-439.

32. Raney AK, Eggers CM, Kline EF, Guidotti LG, Pontoglio M, Yaniv $\mathrm{M}$, et al. Nuclear covalently closed circular viral genomic DNA in the liver of hepatocyte nuclear factor $1 \alpha$-null hepatitis B virus transgenic mice. J Virol 2001;75:2900-2911.

33. Sa-Nguanmoo P, Tanaka Y, Ratanakorn P, Sugiyama M, Murakami $\mathrm{S}$, Payungporn S, et al. Cross-species transmission of gibbon and orangutan hepatitis B virus to uPA/SCID mice with human hepatocytes. Virus Res 2011;158:209-215.

34. Guo H, Jiang D, Zhou T, Cuconati A, Block TM, Guo JT. Characterization of the intracellular deproteinized relaxed circular DNA of hepatitis B virus: an intermediate of covalently closed circular DNA formation. J Virol 2007;81:12472-12484.

35. Kim JW, Lee SH, Park YS, Jeong SH, Kim N, Lee DH. Inhibition of in vitro hepatitis B virus replication by lentivirus-mediated shorthairpin RNA against HBx. Korean J Hepatol 2009;15:15-24.

36. Guo H, Mao R, Block TM, Guo JT. Production and function of the cytoplasmic deproteinized relaxed circular DNA of hepadnaviruses. J Virol 2010;84:387-396.

37. Li GQ, Gu HX, Li D, Xu WZ. Inhibition of Hepatitis B virus cccDNA replication by siRNA. Biochem Biophys Res Commun 2007;355:404-408.

38. Panjaworayan N, Payungporn S, Poovorawan Y, Brown CM. Identification of an effective siRNA target site and functional regulatory elements, within the hepatitis B virus posttranscriptional regulatory element. Virol J 2010;7:216.

39. Starkey JL, Chiari EF, Isom HC. Hepatitis B virus (HBV)-specific short hairpin RNA is capable of reducing the formation of HBV covalently closed circular (CCC) DNA but has no effect on established CCCDNA in vitro. J Gen Virol 2009;90:115-126.

40. Tangkijvanich P, Komolmit P, Mahachai V, Sa-Nguanmoo P, Theamboonlers A, Poovorawan Y. Comparison between quantitative hepatitis B surface antigen, hepatitis B e-antigen and hepatitis B virus DNA levels for predicting virological response to pegylated interferon$\alpha-2 b$ therapy in hepatitis B e-antigen-positive chronic hepatitis B. Hepatol Res 2010;40:269-277.

41. Sung JJ, Wong ML, Bowden S, Liew CT, Hui AY, Wong VW, et al. Intrahepatic hepatitis B virus covalently closed circular DNA can be a predictor of sustained response to therapy. Gastroenterology 2005;128:1890-1897.

42. Takkenberg B, Terpstra V, Zaaijer H, Weegink C, Dijkgraaf M, Jansen $\mathrm{P}$, et al. Intrahepatic response markers in chronic hepatitis B patients treated with peginterferon $\alpha-2 \mathrm{a}$ and adefovir. J Gastroenterol Hepatol 2011;26:1527-1535.

43. Wursthorn K, Lutgehetmann M, Dandri M, Volz T, Buggisch P, Zollner B, et al. Peginterferon $\alpha-2 b$ plus adefovir induce strong cccDNA decline and HBsAg reduction in patients with chronic hepatitis B. Hepatology 2006;44:675-684.

44. Chong CL, Chen ML, Wu YC, Tsai KN, Huang CC, Hu CP, et al. Dynamics of HBV cccDNA expression and transcription in different cell growth phase. J Biomed Sci 2011;18:96.

45. Yuen MF, Wong DK, Sum SS, Yuan HJ, Yuen JC, Chan AO, et al. Effect of lamivudine therapy on the serum covalently closed-circular (ccc) DNA of chronic hepatitis B infection. Am J Gastroenterol 2005;100:1099-1103.

46. Soemohardjo S. New options in the treatment of chronic hepatitis. Adv Exp Med Biol 2003;531:191-198.

47. Delmas J, Schorr O, Jamard C, Gibbs C, Trépo C, Hantz O, et al. Inhibitory effect of adefovir on viral DNA synthesis and covalently closed circular DNA formation in duck hepatitis B virus-infected hepatocytes in vivo and in vitro. Antimicrob Agents Chemother 2002;46:425-433.

48. Werle-Lapostolle B, Bowden S, Locarnini S, Wursthorn K, Petersen J, Lau G, et al. Persistence of cccDNA during the natural history of chronic hepatitis B and decline during adefovir dipivoxil therapy. 
Gastroenterology 2004;126:1750-1758.

49. Cheng PN, Liu WC, Tsai HW, Wu IC, Chang TT, Young KC. Association of intrahepatic cccDNA reduction with the improvement of liver histology in chronic hepatitis B patients receiving oral antiviral agents. J Med Virol 2011;83:602-607.

50. Wong DK, Yuen MF, Ngai VW, Fung J, Lai CL. One-year entecavir or lamivudine therapy results in reduction of hepatitis $B$ virus intrahepatic covalently closed circular DNA levels. Antivir Ther 2006;11:909-916.

51. Reaiche GY, Le Mire MF, Mason WS, Jilbert AR. The persistence in the liver of residual duck hepatitis B virus covalently closed circular DNA is not dependent upon new viral DNA synthesis. Virology 2010;406:286-292.

52. Anderson DL. Clevudine for hepatitis B. Drugs Today (Barc). 2009;45:331-350.

53. Seignères B, Martin P, Werle B, Schorr O, Jamard C, Rimsky L, et al. Effects of pyrimidine and purine analog combinations in the duck hepatitis B virus infection model. Antimicrob Agents Chemother 2003;47:1842-1852.

54. Quintero A, Fabbro R, Maillo M, Barrios M, Milano MB, Fernández $\mathrm{A}$, et al. Inhibition of hepatitis B virus and human immunodeficiency virus (HIV-1) replication by Warscewiczia coccinea (Vahl) K1. (Rubiaceae) ethanol extract. Nat Prod Res 2011;25:1565-1569.

55. Gong ZJ, De Meyer S, Clarysse C, Verslype C, Neyts J, De Clercq E, et al. Mycophenolic acid, an immunosuppressive agent, inhibits HBV replication in vitro. J Viral Hepat 1999;6:229-236.

56. Zimmerman KA, Fischer KP, Joyce MA, Tyrrell DL. Zinc finger proteins designed to specifically target duck hepatitis B virus covalently closed circular DNA inhibit viral transcription in tissue culture. J Virol 2008;82:8013-8021. 